\title{
Talents and Interests: A Hegelian Moral Psychology
}

\author{
Christopher L. Yeomans
}

\begin{abstract}
One of the reasons why there is no Hegelian school in contemporary ethics in the way that there are Kantian, Humean and Aristotelian schools is because Hegelians have been unable to clearly articulate the Hegelian alternative to those schools' moral psychologies, i.e., to present a Hegelian model of the motivation to, perception of, and responsibility for moral action. Here it is argued that in its most basic terms Hegel's model can be understood as follows: the agent acts in a responsible and thus paradigmatic sense when she identifies as reasons those motivations which are grounded in his or her talents and support actions that are likely to develop those talents in ways suggested by his or her interests.
\end{abstract}

At the beginning of his recent book, Hegel's Conscience, Dean Moyar considers the reasons why there is no Hegelian school in contemporary ethics in the way that there are Kantian, Humean and Aristotelian schools:

The final, and in my view decisive reason for the absence of Hegelian ethics is the lack of an accessible account of Hegel's conception of practical reason. Aristotelians can invoke the virtuous person who possesses practical wisdom and who is able to appropriately 'perceive' particular situations; Humeans have a clear and commonsensical belief-desire model; Kantians have a decision procedure in the Categorical Imperative and an attendant moral psychology of respect for the law; and utilitarians have the intuitive goal of maximizing the good consequences of one's action. Hegel does not give us anything so clear-cut at the level of individual reasoning, and without an intuitive account of what the Hegelian agent does, it is hard to see how Hegel's ethics can secure a place to compete against the other theories (Moyar 2011: 8).

I think that Moyar is fundamentally right in this assessment, and the aim of this essay is to redress the deficiency at the level of moral psychology, particularly in comparison 
with Humean and Kantian approaches. By 'moral psychology' I mean broadly a model of the motivation to, perception of, and responsibility for moral action. Within the terms of this project, Hegel's basic model can be articulated as follows: the agent acts in a responsible and thus paradigmatic sense when she identifies as reasons those motivations which are grounded in his or her talents and support actions that are likely to develop those talents in ways suggested by his or her interests.

While I believe that my proposal is broadly compatible with many contemporary but more abstract interpretations of Hegel's account of practical reason and with some prominent views in contemporary moral psychology, demonstrating neither is my primary purpose here. Instead, I want to flesh out Hegel's account as one of contemporary appeal and intuitive accuracy. Because for Hegel, the distinctive moral value developed within this moral psychology is the expression of free individuality, we can orient that appeal by beginning with Hegel's summary of his critical appraisal of Kant's ethics in his lectures on the history of philosophy: 'What merits the name of truth in the Kantian philosophy, is that thinking is grasped as concrete in itself, self-determining itself [sich selbst bestimmend]; thus freedom is recognized' (VGP 331). ${ }^{1}$ But: '[the Kantian philosophy] does not know how to become master of the individuality of selfconsciousness; [it] describes reason very well, but does this in a thoughtless, empirical way by which it again robs itself of its truth' (VGP 332-3). Hegel suggests, then, that Kant's groundbreaking discovery of autonomous practical reason is still shrouded in vestiges of an empiricist account of individual awareness of and motivation by moral features of action. What a Hegelian moral psychology needs to do, then, is to provide a non-empiricist account of the individuality of selfdetermination, i.e., a non-empiricist account of internal motivation.

In Hegel's Phenomenology of Spirit, the best place to look for such an account is in the section somewhat oddly entitled 'the Spiritual Animal Kingdom'. That section follows directly from the section on Active Reason in which Hegel engages with specifically empiricist moral psychologies (in Pleasure and Necessity and the Law of the Heart) and with the Kantian doctrine of virtue (in Virtue and the Way of the World). There, Hegel found fault with these moral psychologies precisely for their inability to specify motivations with which the individual can identify as reasons. This difficulty is conceptualized as the problem that if I do not have an account of myself as the source of my action, then I cannot know myself as an individual by acting. Since Kant's Doctrine of Virtue is the point in his philosophy at which he goes the furthest in attempting to explain the individuality of practical reason, the criticism of Kant in this part of the 


\section{Christopher L. Yeomans}

Phenomenology can be considered a detailed elaboration of the complaint registered in summary form in the lectures on the history of philosophy quoted in the previous paragraph. And since the main stumbling point for both Fichte's and Kant's theories of virtue is the duty of self-development, i.e., the duty to self to develop our own talents, it is not surprising that this moral psychology is explicitly focused on the relation between talents and interests.

In PS 401/PG 296-8, Hegel introduces talents as a way of articulating the experience of action for an individual who finds her social and natural environment to be supportive of her individual agency (i.e., who finds their agency to be already a part of the universal structure of the world around them). ${ }^{2}$ Talents are part of the agent's 'original determinate nature': they precede action in some sense, and they are distinct from the characters of other agents. But talents are more than just dispositions or capacities to be triggered by external stimuli. The agent with talents does not stand opposed to the world of public objects around them, but somehow constitutes that world. Talents, then, are the circumstances of action when understood as internal to the individual in some way: 'a set of given circumstances which are in themselves the individual's own original nature...' Circumstances as viewed through the lens of talents are the inner means by which we translate our ends into reality. But because of this close connection between given context and talent, proximally talent appears to the agent as something given rather than chosen.

Because talents are ways of appropriating and using physical objects (including our own bodies), talents are a way in which we locate agents in the circumstances of actions. In this respect they play a similar role to belief in contemporary causal accounts of action. The belief connects my desire for some end to the circumstances by conceiving of the circumstances as a means to that end. Talents do the same by specifying kinds of activities by which the agent is effective at turning circumstances into resources for action. For this very reason, what counts as a talent is determined in part by the relevant circumstances. Only because of the relative solidity of the ground under us and the strength of gravity are running and jumping talents for human beings, since they are ways of making secure footholds and gravity's resistance into means for our ends of getting to certain places. Merpeople cannot have the talents of running and jumping in their undersea environment.

The exercise of talents becomes an explicit form of individuality when talents are appropriated by interests, i.e., when the agent self-reflectively chooses those talents (and thus the circumstances of her action) as her own. Then we get the real process of action, in which our interest in an action identifies aspects of the circumstances that are rendered significant by the talents we possess: 'But the actual means and the real transition are the unity of talent with the nature of the matter in hand, present in that interest.' The process of action is one of unifying the ends and the means through the coordination of talents and interests to produce an action or work. 
Interests are another way of locating the agent in their circumstances. Our interests are those things about which we feel either concern or curiosity. For our purposes, the crucial feature of both concern and curiosity is the way that they draw us out of ourselves into identification with something or someone other than us. Compassion is a kind of concern for another's well-being, and curiosity is a sense that information to be learned from something as yet unknown matters to me in some sense, even if I cannot make clear what that sense is. Concern and curiosity are ways in which the circumstances of the world come to take on the shape of the self for us, i.e., ways in which we feel ourselves in the world. A world for which we had no concerns and about which we were not curious would not be our world at all; it would not be our home. As Terry Pinkard has pointed out, on Hegel's conception we must first determine who we are by sifting through the world of our autobiography and separating those parts of worldly events that are accurate expressions of our character from those that are inaccurate, and the notion of interest is Hegel's theoretical means for judging which is which (Pinkard 1996: 116).

If talents represent the way in which the world makes us its own denizens, interests represent the way in which we make the world our own world. Interests play a role somewhat similar to desire in contemporary causal accounts, in the sense that they represent the directedness of the agent. After all, a picture of agency is supposed to be a picture of self-determination, of the sense in which the agent originates their action. Interests express the agent's self-directedness towards the world, and thus the sense in which they are agents rather than patients.

But I have so far left out the most distinctive element of Hegel's account: the heart of the matter, which is present in the interest, or what Hegel calls the Sache selbst. It is not enough, in Hegel's view, that I identify with one of my talents and seek to exercise it in the proper circumstances. The interest must further invoke a deep sense of significance that connects it with others involved in similar projects. That is, we must be animated in the use of our talents by a universal sense of importance that in principle exceeds any work that we might produce as a result of our actions.

In order to see why this element is necessary for us to have action in the true sense of the term, it is important to step back a bit and remember that the investigation of the Phenomenology is the attempt to find an adequate object and mode of knowledge, and Hegel quickly argues that such knowledge can only be self-knowledge. So the spiritual animal is being auditioned for the role of adequate self-knower, and the 'heart of the matter' is introduced as a way of solving a certain problem with the view. On the basic view, you begin with an initially loose connection between the inner means (talents and circumstances) of your action and your potential ends (as determined by your interests). Then the interest-guided exercise of talents brings the two together in an actual means that 


\section{Christopher L. Yeomans}

just is the expression of the end in the production of some kind of work. But as anyone who has ever re-read their own writing will testify, the sense of the unity of the elements that is present in the actual process of writing is soon lost in reflection on the work (PS $9404 /$ PG 300-1). As a mere existing thing, then, the work cannot provide us with a basis for adequate knowledge of ourselves as the integrated system of talents and interests. But the ongoing project of reflecting on our work and trying to make it better - i.e., trying to develop means adequate to our ends — can provide the basis for such self-knowledge (PS $\mid 407 /$ PG 302-3). So once the view is made dynamic and interpretive, it requires this sense of significance and purpose exceeding all individual products. This is therefore action that takes the form of holding particular and contingent elements together in a universal sense of the project (PS $\uparrow 408 /$ PG 303-4).

As an example, the heart of the matter for a particular musician is probably best understood as a particular movement or tradition of music. The pianist must be motivated by a sense of what music can accomplish and what counts as good music, a sense that exceeds any particular piece of music and which provides her the standpoint to integrate, e.g., one of her compositions or performances into her longer-term project of self-hood by finding even the disintegrated features of the composition or performance to provide evidence of her access to an integrated sense of music that remains to be produced. But this sense of the fundamental significance of music extends beyond the modification of products or performances to include the modification of the individual herself: she may need to develop her talents in different directions to properly express herself, and her interests may shift with exposure to different musical movements. But because individual musical projects are the only expression and reality of musical movements, her interestguided use of talents changes the heart of the matter as well. ${ }^{3}$

\section{II}

As part of the broadly naturalistic bias of the contemporary philosophy of action, issues of explanation loom large. Though there is a tendency in the Hegel literature to dismiss these concerns, I think they are real enough so long as 'explanation' is not understood in a merely narrowly, efficiently causal way. ${ }^{4}$ Backing away from the text of the Phenomenology for a moment, one of the ways to see the appeal of Hegel's model is to see the way that it provides non-empiricist explanations of actions and therefore counts as a rational reconstruction of our everyday practice of understanding agency. In terms of providing explanatory resources for actions, the model suggests four basic kinds of explananda, i.e., four different kinds of things that might fill the gap in our understanding which motivates a request for an explanation. ${ }^{5}$ To begin with, we might actually 
cite some aspect of the physical circumstances as explanation. The most basic form of such an explanation is certainly George Mallory's explanation for why he climbed Mt. Everest: because it is there. In the same vein, a surfer might explain why he surfed early in the morning (an apparent incongruity given the personalities of most surfers) by appeal to the fact that the winds are gentler in the morning and thus the waves have a better shape.

A second common kind of explanation is in terms of talent: if we are watching an American football game and you ask me why the fullback carried the ball up the middle, even though there was room to the outside of the line and the holes in the middle were all full with defensive players, I might respond that that kind of running is what he is good at. Sometimes, talent explains its own exercise. In part this is because any successful exercise of a talent is satisfying; in part this is just because people get into habits determined by their talents that are hard to break. We even have a colloquial expression warning of the danger of seeing the world in terms of your own talents: if all you have is a hammer, everything looks like a nail.

We sometimes also explain actions in terms of the presence of common projects. If one asks why the skinny, artistically minded kid from Texas ended up playing American football, the answer might just be something like 'that's what they do there.' Because common projects are the source and context of our interests, and play such an important role in defining our talents, sometimes they can swamp those interests and talents. In that case the incongruity between, e.g., our talents and our actions may generate a request for explanation of the action ('Why did he play football?'), and this request may be answered by appeal to the social projects in which we have been swept up.

The most unlikely candidate for explanans of an action is our interest. On the one hand, this is puzzling, since the interest ties the agent most closely to the action. But this is what accounts for its generally poor suitability as an explanation: what we want explained is some kind of action, and this seems to presuppose that there was an interest. Thus, appeals to interest share the feature of appeals to desire: they appeal to that which is normally presupposed in conceiving of the explanandum as an action at all. But when explanations by appeal to interests are appropriate, they are deeper and more informative than explanations by reference to desire. Appeals to interest implicate the agent's own sense of self, often drawing in a historical element. Thus, the explanation for why one might write a dissertation on Hegel would in all likelihood cite an unexpected interest in Hegel that specified the aspects of Hegel's philosophy that resonated with the author, combined with the kind of historical story that explains how the author came to see herself in Hegel's philosophy. This kind of explanation reflects a deeper rift in the understanding of the person requesting the explanation, and thus requires a longer story about who the agent is in terms of how she has come to see herself in the world. 


\section{Christopher L. Yeomans}

Thus the alternative model suggests as explananda the kinds of things that we naturally say in response to requests for explanation. It is certainly still schematic, but it nonetheless points to the cares and concerns embedded in our everyday appreciation and evaluation of actions.

\section{III}

Corresponding to these four kinds of explanations are four kinds of failures of agency that result from the improper or inadequate participation in the action by each element. When we try to do something for which we have no talent, we frequently embarrass ourselves. At issue is more than simply failing to achieve a goal; even if we do (by luck) achieve the goal, we fail to express who we are in that action. Agency is a kind of effectiveness of the agent, and in such cases the circumstances were effective, not the agent. We will not have the proper basis to pick out the agent as a locus of activity and bearer of responsibility. Consider an example in which I am trying to throw a rock into a pond, and my lack of coordination causes me to miss so badly that the rock hits my friend, who subsequently throws the rock into the pond in disgust. Though there is some sense in which I have accomplished my goal (the rock did end up in the pond, after all), there is another sense in which $I$ didn't accomplish anything. I am not the relevant agent with respect to the rock and the pond; my friend is.

When an agent acts in the absence of appropriate external means in the physical circumstances, she fails to connect with the world. At the outer limits of this case, we will not be able to make sense of the agent as sharing the same world of public objects as we do. Again, this is more than just a question of achieving ends or satisfying desires. Agency is a kind of effectiveness in the world; it is distinguished from fantasy or internal role-playing. When I cannot throw the rock into the pond because I do not see that it is only a part of a much larger boulder, my failure to understand the world has an effect similar to my failure to understand myself in the earlier example. Again, this is true even if a subsequent earthquake knocks the boulder into the bond. The issue is not one of failing to achieve goals, but one of failing to achieve the contemplated interaction with the environment at all. Though these are not the kind of failures of agency that have drawn the attention of philosophers of action, they are common experiences in our lives. What we learn from them is not that we must better calculate means to ends; what we learn is that we are not the people we thought we were, and that the world is not what we thought it was. What we learn is not how to better satisfy our desires, but rather how better to understand our existential situation.

A third distinct kind of failure of agency is action in the absence of socially valued projects. In an important sense, this is a more significant failure than the 
two already discussed, since it reflects a failure of the agent to see herself as human in the way that this is humanity is reflected by those around the agent. Our sense of what counts as human is shaped by our sense of the range of significant human projects that are shared in our social environment. When we act as driven by our own personal interests in the absence of such a supportive sense of social significance, we risk the integrity of our own agency because we act in the absence of a social medium that allows us to recognize ourselves as human agents in the actions we perform. It may therefore not be the fault of the individual agent that they are unable to act in the richest sense of that term. Society may prevent human beings from being agents and thus persons. One paradigm example of this is the predicament of lesbians and gay men in societies that do not acknowledge same-sex relationships as forms of love. In those situations, the lesbian or gay man may be forced into the tragic choice between their own sense of self and obtaining recognition of their humanity. The argument of Hegel's political philosophy is essentially driven by the view that a society that cannot provide such a social medium for self-recognition is unjust. This alternative model provides an articulation of agency that helps to connect the value of agency with the respect accorded to persons by social recognition (in the form of rights, opportunities, rewards, etc.).

We may also fail to act in the richest sense of the term when the action is either not motivated by our interest at all, or our interests are somehow not fully engaged in the action. Whereas in action with lack of talent the reality of our constitution is shown not to correspond to the vision that we have of it, here whatever vision we have is swamped by talent, circumstances, or general projects and is thereby rendered ineffective. In Bertolluci's The Conformist, Marcello lacks the courage to assert his own interests against fascist and traditional social standards; his visibility as an individual is a source of anxiety for him, and he seeks to eliminate that visibility through marriage and through work with the fascist secret police. In the end, the action he has begun to assassinate his former teacher must be carried out by others. Or our best intentions may be trumped by a combination of talents and circumstances. If I watch television or read the newspaper instead of working on this paper, it will not be because of my greater interest in what is on TV or in the paper. Instead, there is a pleasant inertia to be felt in not being an agent for a while, in letting my talent for reading or comprehending cinematic presentations exercise itself effortlessly on whatever subjects are presented to me. Tolstoy captures this phenomenon brilliantly:

Oblonsky subscribed to and read a Liberal paper-not an extreme Liberal paper but one that expressed the opinions of the majority. And although neither science, art, nor politics specially interested him, he firmly held to the opinions of the 


\section{Christopher L. Yeomans}

majority and of his paper on those subjects, changing his views when the majority changed theirs,-or rather, not changing them-they changed imperceptibly of their own accord. Thus Liberalism became habitual to Oblonsky, and he loved his paper as he loved his after-dinner cigar, for the slight mistiness it produced in his brain (Tolstoy 1995: 7-8).

When I write this paper, my sense of self is at stake because of my interest in the subject. But when I read the newspaper nothing is at stake. I am inclined to subsume the classic cases of weakness of will under this model. The key to understanding them is not a conflict of desires, but the comfort in acting without putting our conception of self on the line. It is a perverse form of agency that utilizes the tools of agency to avoid the risks of agency. In one of the classic novels of drug experiences, Hunter S. Thompson begins Fear and Loathing in Las Vegas with the epigraph from Samuel Johnson: "He who makes a beast of himself gets rid of the pain of being a man." Though certainly not all intoxication is the result of weakness of will, I suspect that this self-forgetfulness or non-agency is at the heart of the phenomenon.

\section{IV}

At this point, we can return to a more textual grounding by exploring the sense in which such a picture is non-'empiricist' in Hegel's distinctive sense of that term in his polemic against Kant's moral psychology. Here we can differentiate five different ways in which Hegel's schema might be considered non-empiricist:

(1) the model describes aspects of a distinctive kind of activity, not kinds of dispositions;

(2) similarly, talents and interests are long-running features, not discrete causal antecedents;

(3) talents and interests are objective in an ordinary, public or social sense, rather than inner mental states;

(4) there is an internal relation between talent and interest as opposed to the external relation between empiricist mental states such as beliefs and desires;

(5) similarly, beliefs and desires are something like properties or states of the agent, but talents and interests constitute the agent.

It may help to get a better grasp of the way in which these features characterize a 'non-empiricist' view by contrasting them with aspects of contemporary (Humean) empiricist causal accounts of action (i.e., belief-desire accounts). 
(1) Activity vs. triggered dispositions. As a point about the will as such, this is one that Hegel makes explicit also in the Philosophy of Right. the will is not just a possibility, predisposition, or capacity (potentia), but the infinite in actuality (infinitum actu)' (PR§22). But Hegel is explicit about this in the Phenomenology as well, claiming that agency cannot be conceived as a potential that is made actual through human efforts, but rather as something very real in the world that is simply expressed through action (PS $\mid 391 /$ PG 290). ${ }^{6}$ As Allen Wood has noted, this idea is closely connected with the notion that freedom is a good, since it makes sense to think of the good as something actual rather than something merely potential (1990: 40).

The sticking point here might seem to be talent, since the most natural way to think about human talents is as a kind of capacity, but it makes all the difference whether one thinks of them as dispositions to be triggered by external events or as activities of the agent. Take the example of a gymnast's talent. In describing a gymnast as talented, we might be taken to refer to physical capacities that are then triggered in the right circumstances, such as balance or leaping ability. But these are not really what we mean in describing an athlete's talent. One of swimmer Michael Phelps's important features is that he is able to quickly metabolize the lactate produced by his muscles while swimming, which allows him to train more vigorously and to compete in more events. But it seems odd to describe this as part of his talent; it sounds better to say that it is an ability of his body, not of him. It is a kind of mere physical circumstance of his action rather than being a part of his talent.

In describing a gymnast as talented, we might better refer to her ability to translate a coach's directions into bodily awareness and to translate bodily awareness into movement. But each of these abilities is better understood as something that she does as opposed to dispositions that are triggered. Doing certain things (e.g., training) count as developing the talent because they make possible certain further forms of the same kind of activity (e.g., new routines). This is crucial to Hegel because it is a resource for reconceiving the self-mastery of free agents in a way that does not rely on the distinction between free choice and habits on which Kant insists. Neither talent nor interest is like a habit or a desire that remains dormant until triggered by the right circumstances and thus constitutes a kind of external determination of the will; rather it is an activity of the will that seeks out and constitutes circumstances appropriate for its exercise and development. And in claiming that talents are the self-actualizing good, Hegel shows himself at odds with any view according to which a separate mental state (belief) is required to coordinate the striving of the will (desire) with specific circumstances (PS $\uparrow 386$; PG 286-8).

(2) Long-running features vs. discrete causal antecedents. Kant claims that all ends set prior to moral maxims are empirical grounds and self-seeking, but ends that 


\section{Christopher L. Yeomans}

result from maxims adopted as required by the concept of duty can be distinctively moral. ${ }^{7}$ Hegel rejects this conception on the grounds that the same role is played by the specific interests of the agent in both cases: a universal is given life, a concrete form, by the way in which the agent takes an interest in a particular situation (PS $\$ 385 / \mathrm{PG} 286$ ). The prior/posterior distinction, whether regarded as an issue of the causal history of the action or of the constructed justification for it, is for Hegel an essentially superficial distinction that cannot generate the deep moral difference between the two kinds of ends as required by Kant's theory of virtue. Put more positively, Hegel's model conceives of agency less in terms of motivation than in terms of characteristic processes. Rather than identifying the phenomenon of agency by referring to mental events (beliefs and desires) that cause other mental events (intentions), this model refers to the shape of the activity that includes the action as a proper part. Whereas beliefs and desires are necessarily antecedent events that may or may not extend beyond the temporal threshold of their production of the intention or action, talents and interests are necessarily long-running elements that persist throughout the timeframe of action and in fact extend beyond it in the ordinary case.

(3) Public features vs. inner mental states. It is perhaps easiest to see here Hegel's difference from any empiricist view. This difference becomes most apparent in Hegel's inclusion of the Sache selbst or heart of the matter in his basic schema for action, but let us put that aside for the moment in order to see how even those other elements of Hegel's schema appear to be quite different from their empiricist counterparts. Talents needn't be thought of as distinctively internal to the individual; because they are things that the individual does in the world they are publicly available in a way that beliefs and desires are not. Talents therefore tie agency to the distinctive constitution of each agent in a way that does not invoke the distinction between inner mental states and outer physical activity. Though different agents have different talents, whether they have that talent is an objective question to be determined by the interpretation of action; the agent herself has no privileged first-person access to this element. This public aspect of talents and interests is precisely what generates the problems of hypocrisy and deception later in the section on the spiritual animal kingdom (PS $\uparrow 415 /$ PG 307-8).

As with talents, interests are an objective fact about the agent, rather than an internal mental state to be introspected. If I claim to have an interest in playing the piano, but I never practice nor do I listen to recorded piano music, you would be within your rights to reply that I do not really have an interest in piano. I am either self-deceived or I am lying. My interests are determined by interpretation of what I do, and this is a public matter. Furthermore, interests also have a reciprocal relationship to the physical circumstances of actions. Certain interests are likely to develop only in certain circumstances (e.g., the interest in surfing in places where the waves are good). More subtly, talents are going to play a role in 
specifying what count as the physical circumstances of the action: of all the infinite number of facts about the agent's environment at the time of action, talents help to pick out which are relevant as causal conditions for the activity of the agent.

But Hegel claims that this coordination of talents and circumstances remains inward in some contrastive sense: a mere inner as opposed to an actual means (PS 401; PG 297). Though it is clear how talents and context together form a means for bringing about ends, it is less than clear what it means to say that they are distinctively 'inner.' It is particularly puzzling because talents and circumstances at first appear to be the elements in Hegel's schema that have a primarily objective source (i.e., they are the two elements that most appear to the agent to be given prior to the activity of subjectivity). One expects the inner to be identified with the subjective or distinctively mental, but here Hegel makes the reverse identification. By contrast, the actual means to the end invokes the elements of the schema that have a fundamentally subjective source (i.e., those which appear to be characterized by mental activity): the interest and the Sache selbst. Hegel has completely reversed the usual empirical understanding of inner and outer in action. What sense can be given to this reversal?

Fundamentally, the reversal derives from the point we saw above in (1), namely that agency is an actuality rather than a capacity. At the same time, action is always a form of negativity and therefore of change (PS $1399 / \mathrm{PG} 295)$. In the context of the Phenomenology, after exhausting all of the historically available understandings of the change enacted by action in terms of realizing some potential, and before turning to a discussion of the social institutions (spirit) that will give concrete goals pursued by individuals, Hegel must specify a new form of action-induced change from one state of existence into another state of existence. The distinction between the inner and the actual is maintained, but now must be given a new interpretation. On this interpretation, the inner is that which remains open to alternate possible futures. Thus Hegel claims that talents represent "a simple principle, a transparent universal element...” (PS 1398; PG 294-5). This is an element that provides the possibility of different realizations of the agent's character in action. Hegel's view is that the truth underlying Kant's apparent confusion about the proper constraint on the development of talents is that talents play the role of a kind of natural universal that is self-specifying, i.e., a telic universal that includes differential possible routes of development or realization. Once Fichte has deepened and radicalized Kant's own insight into the role of effectiveness in distinguishing between true willing and mere wishing, the inner/ outer distinction is fundamentally changed by the recognition that what ends one can set depends, in part, on what one can actually do. ${ }^{9}$ This is why Hegelian talents are individuated forms of the capacity to set ends, in the Kantian sense.

On Hegel's view, it is the interest the agent takes in her action that answers the questions, 'whether or what is to be done here.' That is, the interest provides 


\section{Christopher L. Yeomans}

the resolution to the open future presented by the complex of talents and circumstances, and thus when we exercise our talents while guided by our interests, our action is an actual means for translating ends into existence. But the open future is represented neither by a mere potential nor by an indeterminate state of being or character; rather it is represented by a completely determinate original nature and the circumstances connected with it. This is what Hegel means in describing the original nature as a 'determinate range' that is then given a specific form of life by its animating principle (PS $\$ 398 /$ PG 216). Talents are inner in the sense that their significance is only made clear by the animating force of interest.

Let us cut through this abstraction with an example: the action of practicing the piano. Though talents and circumstances lay dormant until the interest arises to begin the practice session, this is not because they are mere potentials. The piano sits there, as real and physically imposing as anything. The pianist's talents remain in her as well in the form of conceptual connections and physical traits (e.g., real neural pathways that are not merely present as dispositions or potentials, but have an actual physical and effective presence). But at the same time, the musical talent and physical presence of the piano and sheet music lay open a future that can be determined in different ways: different pieces can be practiced, in different ways, etc. But another crucial element is the way in which the talents and the physical objects themselves are transformed. Every note played changes the piano in some way, and what and how the pianist practices will shape her skill in a certain way. So there is a mutual interaction of interest, talent, and physical object that partially constitutes the agency of the pianist. ${ }^{10}$ But this necessary mutual interaction pushes decisively beyond Kant's insistence on internal as opposed to external grounds of the will.

(4) Internal vs. external relations. Talents and interests are internally related in a way that distinguishes them quite sharply from beliefs and desires as elements in a basic model. ${ }^{11}$ But this also distinguishes their relation sharply from the relation between natural inclinations and rational respect from the moral law in the Kantian view. Whereas neither beliefs and desires, nor inclinations and rational maxims are intrinsically related to one another, talents and interests have a naturally dialectical relationship in which they each shape the other. Talents naturally suggest interests, as we tend to see ourselves in what we do best; and interests are pursued through activities that develop talents and make them both richer and more determinate. ${ }^{12}$ The two are engaged in a mutual granting of significance or specification of what counts as talent or circumstance. But talents are inherently oriented towards goals (one can waste a talent, but not a capacity), and so to conceive of circumstances as the location for the exercise of talents is to give those circumstances the form of the self by determining their significance by reference to the goal-orientation of an agent, and an interest then makes this explicit. ${ }^{13}$ A musician might have an initial talent for remembering musical ideas 
and correlating sounds to their notation on the page. This talent might generate an interest in playing music under the right circumstances. This interest then develops the talent through practice that not only increases the talent (e.g., more complex musical ideas can be remembered and more complex notation processed while sight-reading), but also orients it towards specific kinds of performances (e.g., improvisation or interpretation of scores). This internal relation comes to Hegel out of meditation on the role in Kant and Fichte of effectiveness in mediating between talents on the one hand and setting ends on the other. The fact that effectiveness is shot through the whole process of agency means that there is no point in tracing any specific, prioritized pathway of causal determination from one to another, which is the stumbling block for all empiricist causal theories of agency (i.e., the problem of wayward causal chains). ${ }^{14}$ Instead, there is an inherently recursive process of mutual talent and interest formation and development. This is part of what Hegel was insisting on when he claimed that talents and interests together are both the material and the purpose of activity, and the element that absorbs the shape of individuality (PS $\$ 396 /$ PG 293 and PS $1401 /$ PG 296-8). Unlike laws that are applied or instantiated, talents and interests are modified in the process of their exercise and pursuit.

5. Constituting character vs. states as properties. By 'states as properties' I do not mean to name some specific metaphysical claim, but rather a specific practical problem for empiricist theories of agency regarding the distance between specific motivations and the self, a problem that often goes by the name 'weakness of will.' The problem has been nicely generalized as a problem for causal theories by David Velleman, who argues that such theories do not require any substantial role for the agent in her own action, since the agent can in principle distance herself from any of her desires or intentions. In cases of weakness of will, for example, I seem to be moved to action by desires that are, in some sense, external to me. Therefore, the common model of action is a model of those of our actions in which we do not play a central role-but surely these are derivative, borderline cases of action rather than the paradigmatic cases. Adding a hierarchical element does not appear to help, since I can disassociate myself from my second-order desires just as readily as from my first-order desires.

Thus Velleman has some sympathy with Roderick Chisholm's claim that such a model is not really a model of agency at all. But rather than endorse Chisholm's appeal to the agent as a kind of primitive notion on par with desire or intention, Velleman claims that the agent intervenes between her desires and beliefs and her intentions in the form of a motivation to act for reasons. The ' $\mathrm{T}$ ' in action is to be found in the 'desire to act in accordance with reasons, a desire that produces behavior, in your name, by adding its motivational force to that of whichever motives appear to provide the strongest reasons for acting, just as you are said to throw your weight behind them' (Velleman 2000: 141). To put this 


\section{Christopher L. Yeomans}

from the agent's perspective, she can recognize herself in her action when she notices the role played by this motivation to act for reasons.

The problem with Velleman's (broadly Kantian) emended view is that it appears to lose the agent in a different way. If the agent is to be identified with the abstract motivation to act for reasons, then the agent is to be identified with a motivation that all agents necessarily have in common rather than with some aspect of their agency that distinguishes one agent from another. So if the desirebelief model loses its grip on the agent because it does not include any element from which the agent cannot disassociate herself, Velleman's model loses the agent because it appeals to an element from which no agent can disassociate themselves and thus which cannot pick them out as an individual agent. ${ }^{15}$ This is also why contemporary, broadly Kantian accounts of Hegel's theory of practical reason in terms of acting on a reason as opposed to acting on a given motivation are, by themselves, insufficient to respond to the challenge of articulating free individuality that Hegel has set himself by his critique of Kant.

Hegel's response to precisely such difficulties in Kant and Fichte is an expressivist moral psychology in which the agent identifies as reasons those motivations which are grounded in his or her talents and support actions that are likely to develop those talents in ways suggested by his or her interests. By 'expressivist,' I mean to describe Hegel's claim that the true ends of action have to have as their content the very character or personality of the agent herself. Hegel motivates this expressivism by contrasting it with the mistake of thinking that an agent's ends could somehow be distinct from his or her character (i.e., of an agent 'wanting to give reality to a different content' than their character). In such a case, the acting agent would be 'a nothing working towards nothing' (PS 401/PG296). This is Hegel's way of articulating the basic worry that Velleman formulates as the concern that I lose the agent in the story of action. ${ }^{16}$ Hegel's more radical formulation expresses, in quite graphic terms, the disappearance of the agent in action-but from the first-person perspective as well as from the third-person perspective. Hegel is concerned with mistaken selfunderstandings of action in addition to theoretical mistakes in the philosophy of action. Or rather, Hegel is concerned with such theoretical mistakes as the mistakes of self-reflective agents in action as much as the mistakes of theorists of action. ${ }^{17}$ The mistakes of such agents can lead to their actual disappearance to themselves in their lives, and not just the theoretical elision of the agent in our philosophical theories. It is precisely this concern with self-knowledge that animates Hegel's account, and why he generalizes Kant's recognition that individual interest is necessary to specify our deepest moral duties of virtue into the claim that 'all the things which engage individuality are ends in themselves, and the use of powers, along with playing the game of giving them outward expression is what gives life to what otherwise would be the dead in-itself’ (PS \393/PG 291). 
The schema of talents and interests addresses the interface between self and context that is contained in Hegel's fundamental formulation of freedom: being at home with oneself in the other. ${ }^{18}$ More than anyone else in the tradition, Hegel tries to work out in detail the way in which individual agency is compatible with the deep ties and influences that come with being a social and embodied subject. ${ }^{19}$ The schema isolates as basic elements of agency those features that describe the self/context interface in both passive and active terms. Put another way, it is a description of the integration of internal (individual) and external (social) points of view from the internal point of view: it is what spirit looks like from the inside out. ${ }^{20}$ As a result it gives the phenomenological form of awareness of spirit, which is in part the way in which the social substance is animated by the individual. Thus this schema helps to combat the false impression that Hegel's spirit is social substance from the top down, particularly in the Phenomenology.

\section{V}

A further way to see the value of the notions of talent and interest is to locate them in Hegel's own schematic presentation of his distinctive conception of the infinitely free will in $\$ \S 21-7$ of the Philosophy of Right, which culminates in his cryptic notion of 'the free will which wills the free will. ${ }^{21}$ This group of sections takes up from Hegel's criticism of empiricist (including Kantian) moral psychologies as representing an indeterminate "formal universality" in contrast with the concrete content of the various drives, and thus this group of passages is in a structurally parallel position to the Spiritual Animal Kingdom of the Phenomenology. Here I want to suggest that we can use 'interest' and 'talent' to interpret Hegel's master presentation of the distinction between the subjective and objective sides of the free will within this group of passages. In $\$ 25$, he presents the aspects of the subjectivity of the will as follows:

(1) formal self-certainty;

(2) the particularity of free choice (Willkür) and contingent content; and

(3) the one-sided form of self-consciousness as an unaccomplished end.

Let us think a bit further about what these three aspects of subjectivity mean as different kinds or senses of interest, and specifically individual interest:

(1) Formal self-certainty. The term Hegel uses here for 'certainty' is Gewißheit. 'die reine Gewißheit seiner selbst, unterschieden von der Wabrheit [the pure certainty of itself, differentiated from the truth]' (PR§25). This is, of course, a familiar distinction from Hegel's Phenomenology, where each stage of consciousness presents distinctive conceptions of certainty and truth, and the question is 


\section{Christopher L. Yeomans}

whether they fit together as advertised. But both in the Phenomenology and here in the Philosophy of Right, a better (though admittedly less standard) translation of 'Gewijheit might be 'awareness,' so long as one understands such an awareness to make a claim to veridicality. ${ }^{22}$ This is related to the notion of an interest in two ways. First, because of the way in which framing some object in terms of the form of subjectivity constitutes an appropriation on Hegel's view, i.e., which turns a fact or purpose into a content of a particular subject: 'Thus something is called subjective that belongs to consciousness as what is my own [als dem Meinigen angebörf...A All drives for knowledge and culture consist in this sense, that what is also become my own, posited in my subjectivity' (VPR III, 157). The fact that this can be put in both the theoretical and the practical register indicates the breadth of the point Hegel is trying to make here: to take an interest in something is to see oneself in it, which is in a certain sense to see oneself confirmed in it. ${ }^{23}$

The second sense in which self-awareness is a kind of interest is concerned more directly with the reflexivity of self-awareness: 'I am a subject, I am I, so [subjectivity] is my pure interiority, that I reflect myself into myself, the selfconsciousness that I am I myself' (VPR IV, 144). Given the magnification of the self-reflection of the I described here, it is not surprising that Fichte makes this connection to interest, though originally in a negative mode. Fichte holds that for truly ethical, disinterested action, the agent must forget himself, even trying to avoid having any actual perception of himself as an individual (since this would be awareness of his inadequacy as a tool of reason). ${ }^{24}$ The flip side of this coin is that any self-awareness is an interest, i.e., an investment in one's self. On Hegel's more positive employment of this basic recognition - motivated by the idea that all successful agency involves an element of (perceptible) self-confirmation-this awareness is an inherent part of free, individual subjectivity. An interest thus expresses who I take myself to be, which is in principle distinguishable from who I really am. Particularly in an expressivist moral psychology such as Hegel's, such self-awareness is a commitment to who I want to be, i.e., what implicit nature I want to express. So I have not merely a theoretical interest in confirming my self-impression, but that impression itself has a normative element that makes it an interest as well. Because my self-impression is awareness of a free and active being motivated in part by such awareness, it is inherently an action-guiding and -motivating norm. Thus it is not surprising that Hegel associates this 'pure self-awareness' with the Kantian distinction between a free subject and a mere thing (VPR IV, 144). One of the respects in which I take myself is qua free, and when I am coerced or forced merely to obey authority this commitment is challenged by the truth of reality. ${ }^{25}$

(2) Willkür and contingent content. This is the easiest of the three senses of subjectivity to see in the notion of an interest. The notion of a free choice between options and a diversity of goals and objects characterizes the plurality of 
interests that ramifies into everything from professions to hobbies to 'lifestyles.' The diversity of psychic investment in objects, where that investment is grounded only in the decision to take an interest and in the presence of the object is a central feature of our modern understanding of the will. Thus Hegel takes the opportunity to emphasize that an exclusive valorization of subjectivity in this sense in the root of vanity (VPR III, 157) and evil (VPR IV, 144).

(3) Unaccomplished end. Here we have the sense of 'subjective will' that is perhaps closest to the current philosophical understanding of the term, i.e., something like a desire yet to be satisfied. The drive of the subjective will is to realize itself, and though it is understood as contrasted with objectivity there is a kind of internal connection between the two. This is represented in the idea sometimes present in the analytic philosophy of action that there is a necessary relation between an intention and a corresponding action such that, absent any intervening conditions, the agent necessarily acts on that intention. In his lectures, Hegel draws out the sense in which this is an interest by pointing to its reciprocal relation to the first aspect of the subjectivity of the will, i.e., self-certainty: 'All human doing is making the subjective into the objective and then again to possess oneself of everything objective, so that it is my own. This infinite avarice is subjectivity' (VPR III, 159). To take an interest in something is not to be a passive yet consistent observer, but rather to desire one outcome rather than another. If someone says that they have a great interest in politics, but do not care who gets elected or what laws are passed, then it would be doubtful whether they have accurately described their attitude. An interest is aimed at objectivity and is to that extent both deficient in virtue of and yet enriched by that internal connection.

Hegel describes the objectivity of the will in three ways, each of which is clearly meant to be parallel to the aspects of subjectivity (PR§26):

(1) the will, der 'sich selbst zu seiner Bestimmung hat';

(2) "the will immersed into its object or condition, whatever the content of the latter may be," without the infinite form of self-consciousness; and

(3) external existence as 'die Ausfübrung seiner Zweck.,26

In parallel with the above discussion of interest and subjectivity, let us briefly consider how the notion of talent might regiment Hegel's thought on these three points: ${ }^{27}$

(1) The will that has itself for its own determination. It is in engaging in activities for which I have a talent that I have my own character or vocation (as Bestimmung might also be translated here) as the content of my will. For Hegel, talents are individualized forms of the capacity to set ends (i.e., of 'humanity' in Kant's sense of the term). In his discussion here, Hegel claims that the will which 'has itself as its determination... is thus in conformity with its concept and truly itself 


\section{Christopher L. Yeomans}

[seinem Begriffe gemäß und wabrhaftig ist].' As discussed above, this reference to objectivity as truth is one half of the reference to subjectivity as certainty or awareness. The goal of self-knowledge is to connect awareness with truth.

(2) The will immersed in its conditions. Talent has a way of exercising itself without conscious awareness. So, for example, my daughter often dances without knowing it (e.g., while doing dishes, listening to her mother) and as a child Magic Johnson was always dribbling a basketball wherever he went. The odd collection of adjectives Hegel uses for the will that is objective in this way is telling: 'the childish, ethical, slavish, superstitious and so on. ${ }^{28}$ What they all have in common is doing things because they are done, rather than as consciously justified by any particular reasoning process. At an individual level, this basic pattern of actuality is specified by our habitual exercises of talents of all sorts, and we modify, e.g., our speaking accent or the way we mount a bicycle with great difficulty. Part of the reason we can change them only with difficulty is because the effectiveness of our talents organizes our perception of the environment in which we act. It is, in fact, somewhat difficult even to bring these objective features of our own self to conscious awareness so as to make them subject to our interest in the way that, for example, a dialogue coach might help an actress to become aware of the difference between her own natural accent and the target accent of her character.

(3) The end realized in external existence. Hegel specifically associates the development of talent with this aspect of objectivity in his contrasting remarks on the parallel aspect of subjectivity. In describing the unaccomplished end, Hegel writes, "The child is still undeveloped according to reason, thus subjective in its own self; in its self-consciousness this concept is not yet realized. In unwrought people [Den roben Menschen], their will has not yet come to objectification in themselves', (VPR IV, 144-5). Talents are not just the means for the fulfillment of ends, but their development is also itself the fulfillment of an end. A talent for music allows for effective practicing which then develops the talent itself.

In starting to think of the relation between subjectivity and objectivity on this model, the beginning of PRß26Z is helpful: 'It is usually believed that the subjective and objective are firmly opposed to one another. But this is not the case; they in fact pass over into one another, for they are not abstract determinations like positive and negative, but already have a more concrete significance.' This concrete significance can be understood in terms of the interactions of talents and interests. That is, talents and interests can give us a concrete, phenomenological grip on Hegel's distinctive but abstract logical claim that the subjective and objective 'pass over into each other.'

(1) Self-certainty \& the truth of the will's own vocation. When my talents are sufficient for me to accomplish a goal in which I am interested, my formal sense of self is confirmed substantively as my own vocation, i.e., as accurately 
representing who I am. In this way, this formal self-awareness comes together with truth to generate true self-knowledge-this is 'phenomenology' in the distinctively Hegelian sense, as noted above. Hegel emphasizes this in his account of how individuals come to know themselves as persons: 'The human being, in his immediate existence in himself, is a natural entity, external to his concept; it is only through the training (Ausbildung) of his own body and spirit, essentially by means of his self-consciousness comprehending itself as free, that he takes possession of himself and becomes his own property as distinct from that of others' (PRß57). That is, our practical self-knowledge is not a simple matter of the perception of an object (though it certainly has a perceptual component); rather, we learn what our talents are by learning to use them. Part of concrete self-knowledge (of which the will is essentially a form, on Hegel's view) is recognizing not only where one's skills lie, but also the particular form of one's skills in that area. Some people have musical talent and others do not, but within the first group are those whose skills (e.g., pre-hearing) that are more effectively used in improvisation as opposed to those whose skills (e.g., memorization of extensive passages) are more effectively used in interpretation of a given score. Such self-knowledge is real knowledge, i.e., it is knowledge of an object or of the objectivity of the self.

(2) Willkür and immersion in conditions. Seeing talent as self-exercising (even without explicit consciousness) also helps to see how even the contingent, particular content of the subjective will is in some sense grounded in the nature of the individual (i.e., is an internal moving principle in the Aristotelian sense). Talent illuminates the environment, so that a kitchen counter becomes a barre for my daughter, and an empty water bottle becomes an instrument for Danilo Perez. ${ }^{29}$

Thus when Hegel gets to PR $\$ 27$ in which freedom is made objective both as a rational system of thought and as immediate actuality, the individual form of this is the way that the mutual development of talents and interests shows that the subjective and the objective are internally related, and that the concrete pattern of interest is reflected in the specific skills of the subject.

(3) The realization of ends. Talents and interests can give the connection between the distinctively inner form of subjectivity and external existence as the sphere of the accomplishment of subjective purposes a doubly concrete sense. First, in PR§57, Hegel claims that 'this taking possession of oneself consists also in translating into actuality what one is in terms of one's concept (as possibility, capacity (Vermögen), or predisposition).' Talents are most obviously the means for this translation, but they are also in many cases the realized end.

Second, in a handwritten note to $\$ 57$, Hegel emphasizes that talents are not the same as subjectivity, but are internally related to subjectivity in such a way as to allow their externalization (PR: 125). The concrete ego has capacities and drives that constitute it without being identical to it or entirely under its controlthat control is a practical project, the project of taking possession of oneself. 


\section{Christopher L. Yeomans}

But when these natural drives, dispositions, and capacities are controlled, they are skills (i.e., 'talents' in my reconstructive terminology) that constitute the objective side of the agent and can be even further externalized (e.g., in the products of labor or in athletic performances). Of course, put abstractly, self-constitution looks like impossible bootstrapping; but put in terms of talents and interests, it looks rather mundane.

This allows us to come to Hegel's conception of 'the free will which wills the free will (PR§27). In his lectures, Hegel elaborates on this in the following way: 'It is therefore the absolute drive of the free spirit to achieve this its truth, to make of itself its freedom objective [sich seine Freiheit objective zu machen], in the sense that for it its authentic [wahrhafter] will is its object [Gegenstand] through which the free will itself becomes objective [gegenständlich], and gives it the vocation, to present itself in a world as something existent' (VPR III, 163). It is important here to see the radical nature of Hegel's claim: the free will itself becomes an object, i.e., Gegenstand or something that has a stability and resistance of its own as against the

subjective of which it is the externalized form. ${ }^{30}$ As far as I can see, the term 'talent' answers best to a concept of ordinary human experience that describes a resistant expression of one's subjective interest.

\section{Christopher L. Yeomans \\ Purdue University cyeomans@purdue.edu}

\section{Notes}

\footnotetext{
${ }^{1}$ Abbreviations: VGP: Vorlesungen über die Geschichte der Philosophie III, Vol. 20 in Hegel (1971). PS/PG: Phänomenologie des Geistes (first reference is by paragraph number to Hegel (2008); the second is to Vol. 3 in Hegel (1971). VPR: Vorlesungen über Rechtsphilosophie (Hegel 1974). PR: Grundlinien der Philosophie des Rechts, Vol. 7 in Hegel (1971). EL: Ensyklopädie I: Die Wissenschaft der Logik, Vol. 8 in Hegel (1971).

${ }^{2}$ Unless otherwise noted, all citations and references in this first section are to this paragraph. Here I use 'talent' [Talent] where Hegel discusses “special capacity, talent, character, etc. [besondere Fäbigkeit, Talent, Charakter usf.]" Talent covers the relevant kind of ability in all three terms, and has the additional benefit of better expressing the internal connections between the relevant kinds of abilities, on the one hand, and interests and social projects, on the other. Throughout his corpus, Hegel is remarkably casual in his terminology for this aspect of agency, frequently having lists of rough synonyms as in the passage above, e.g., PS $1385 /$ PG 286: 'gifts, abilities, powvers [Gaben, Fähigkeiten, Kräfte]'; and PR§277Z: 'Capacity, ability, character belong to the particularity of the individual... [Fähigkeit, Geschicklichkeit, Charakter].' At PR§291 he uses
} 


\section{Talents and Interests: A Hegelian Moral Psychology}

Befähigung (skill, aptitude) in a roughly similar sense. On the universal character of talent, see PS $₫ 398 /$ PG 294-5.

3 The points here are connected to Allen Wood's concise explanation of the way in which Hegel's self-actualization theory is different from both deontological and teleological theories: "In such a theory, it is misleading to consider 'self-actualization' as the end or goal of the self... From one point of view, self-actualization is simply a by-product of acting in certain ways, following certain principles and successfully pursuing other ends. But it has the appearance of an end because for a self-actualization theory, these ends have their value and these principles their force because they are the ends and principles of a certain sort of self" (Wood 1990: 31-2).

${ }^{4} \mathrm{I}$ have made this case at length and with Hegelian texts in Yeomans (2011).

${ }^{5}$ The notion of explanation as responding to a gap in our understanding is drawn from Wright (2011).

${ }^{6}$ Terry Pinkard has a very nice summary of the historical context of this idea in Pinkard (1996): 112-5.

${ }^{7}$ In the Doctrine of Virtue (Kant 1996: 6:382).

${ }^{8}$ Pippin emphasizes this aspect of Hegel's theory of agency in the Reason chapter of the Phenomenology, though not as framed specifically in terms of talents and interests (2009: 151-3). In general, this feature has been framed in terms of retrospectivity, though in fact the temporality involved is broader. For a good discussion of this issue and an alternate proposal, see Deligiorgi (2010).

${ }^{9}$ Fichte's System of Ethics is a text which begins with the problem of individual self-appropriation: "to think oneself, merely as oneself, i.e., separated from everything that is not ourselves" (Fichte 1965: Vol. 4, 18 and Fichte 2005: 24). As part of the solution to that problem, Fichte refers the reader to the Foundations of Natural Right, a text which begins with the claim that the finite rational being cannot posit itself as such "without ascribing a free efficacy to itself" (Fichte 1965: Vol. 3, 17 and Fichte 2000: 18). Property right is justified because of the role it plays in solving the problem of individual efficacy: to find ourselves as free requires "that the object in experience that is thought of through the concept of the person's efficacy actually correspond to that concept; what is required, therefore, is that something in the world outside the rational individual follow from the thought of his activity" (Fichte 1965: Vol. 3, 9 and Fichte 2000: 9), and since to posit oneself as an individual is to posit oneself as one among many, it turns out that only on the assumption of a sphere under my exclusive control can my efficacy be made cognizable for me. 10 Thus, contra Moyar (2011: 89n18), the invocation of talents opens agency up to the influence of external conditions precisely by being a way of characterizing them as one's own. As far as I can see, Hegel raises the chicken-and-egg problem of finding a beginning only to dismiss it quickly precisely by reference to the relation of talents and interests.

${ }^{11}$ Of course, one might modify the basic Humean picture to include such an internal relation, thus producing 'besires' instead of distinct beliefs and desires. But one might think that there is always a tension between the basic Humean materials (belief and desire) and understanding them as internally related. For an example of such a tension, consider the dialectic and framing in Zangwill (2008). 


\section{Christopher L. Yeomans}

12 This feature of Hegel's view suggests a certain problem from the Kantian point of view, which is that my interest in morality is pegged to my talent for morality, which might be rather low. On the one hand, Hegel mitigates this problem by not thinking of moral reasons or interests as a distinctive (universal) subset of reasons as opposed to (particular) non-moral reasons. For Hegel, morality is an awareness of one's individual responsibility in all action precisely in holding together the universal and particular aspects, so it is not a talent that one can be without in any fundamental sense (cf. Moyar's interesting conception of "the burden of non-detachment” (2011: §3.5)). On the other hand, Hegel recognizes that certain kinds of talent and activity do not naturally suggest moral interests in the more specific sense of care or concern for others. Specifically, Hegel describes the Gesinnung or disposition of the merchant class that arises in part from their talent for pure exchange through money as: "this pitilessness [Härte] of spirit, in which the particular as completely divested no longer counts,- - strict right, exchange must be honored, regardless of what must perish: family, prosperity, life, etc.complete mercilessness" (Hegel 1976: 269-70).

${ }^{13}$ Thus the connection between talents and interests helps to explain a use of 'interest' noted by Moyar, namely one that he takes "to be synonymous with standing purpose and commitment, but also to include the way that the natural motives are structured through one's attachment to purposes" (2011: 64, emphasis mine).

${ }^{14}$ See Yeomans (2010).

${ }^{15}$ Of course, this assumes that the element that defines the core of agency is also the element that secures personal identity in the sense of making each person/agent the distinct individual that they are. One might deny this - and Velleman appears to in more recent work-but then one loses the connection between agency and personal identity that appears to make us the authors of our own lives in the sense traditionally bound up with concepts of free agency. Thus Velleman's model is structurally unable to serve as a model of self-determination. See particularly the 'Introduction' to Velleman (2006). Nonetheless, it is important not to overgeneralize this point. It is certainly not the case that my interests or talents must be absolutely unique to me-it is not even true that they could be. Widely shared groupings of talents and interests actually facilitate selfindividuation. But there is a necessary mean to the scope of that sharing, and Velleman's Kantian view represents the other extreme, and thus a feature that could individuate human agents as opposed, say, to other animals, but not some particular agent as opposed to another. ${ }^{16}$ For Hegel, the problem is much more acute, since he claims to have shown that knowledge of the world is parasitic on knowledge of the self. Thus, if we cannot know ourselves as individuals we cannot know anything at all. Given the generally naturalistic contemporary background to Velleman's concern, the stakes are not as high: even if I cannot know myself, the validity of science and our perceptual awareness of the world do not hang in the balance. ${ }^{17}$ This is due to a general feature of the Phenomenology, which is that consciousness in general is taken to be self-reflective in the sense of always containing some sort of account of itself, i.e., of how it is trying to know an object.

18 Thus tracing the connection between the spiritual animal kingdom and the duty of virtue to develop talents helps to prevent an overemphasis_common in the secondary literature-on 


\section{Talents and Interests: A Hegelian Moral Psychology}

the negative thrust of the former. Robert Pippin (1993: 75-7) presents this balance concisely, where the commitment to recognized self-realization develops the implicit sociality of talents and interests behind the back of their professed individualistic prudence. Rüdiger Bittner presents only the negative side in framing the section as an argument for the claim that prudence (i.e., practical reason based solely on individual life plans) does not exist. (1989: 149). In my view, talent and interest become distorted ideals in the Spiritual Animal Kingdom because the Sache selbst or heart of the matter remains an empty placeholder and is not yet developed into the specific common social projects in which talents and interests are developed and exercised. In this way the Sache selbst is analogous to the Good in the Philosophy of Right in the sense that for both, their evacuated but proleptic character helps to frame the emptiness objection against Kant as an objection against a view that has retreated from a fuller conception of moral value that is available to it. Only with the specific social relations (in the Spirit chapter of the Phenomenology, and in Ethical Life in the Philosopby of Right) do we have specific principles of judgment to adjudicate the kinds of disputes that arise in the spiritual animal kingdom and thus to curb the prevalence of deception and hypocrisy in personal relations.

${ }^{19}$ Often interpreters identify the spiritual animal kingdom with civil society (e.g., Bloch 1951 and Lukacs 1975). But the breadth of the duty to develop one's talents belies this more narrow identification. This is particularly true if one takes civil society to be identified with the system of needs that sees to the satisfaction of particular and given needs separate from the universality of right (e.g., Blasche (2004: 185)). Certainly talents and interests have a natural element, but the whole point of Hegel's conception of their relation is to show how the givenness of nature is transformed into the expression of free agency (which is the very content of right, on Hegel's view), and furthermore in a rather specifically self-conscious way. Also, the scope of talents is not restricted to civil society among the institutions of ethical life, a fact demonstrated by the importance of Vermögen to the family (see, e.g., Ciavatta (2009: Ch. 6)).

${ }^{20}$ For this reason, it has a similar function to conscience as Moyar understands it (2011: 30). Thus it is not surprising that there are deep structural similarities in the Phenomenology between Hegel's presentation and criticism of the Spiritual Animal Kingdom, on the one hand, and conscience, on the other. In both cases, the positive developments of structures of agency are easily missed amid the charges of hypocrisy. One can see the interrelation of talents and interests as a moral psychology of the way in which agents hold together the specific purpose that describes their particular action, their standing purposes as individuals, and the universal purposes of their institutional context (Moyar 2011: 76).

${ }^{21}$ Cf. the good summary treatment of these passages that ties them back to Hegel's schematic presentation of the will in PR\$\$5-7 in Rose (2007: 52-54).

22 This was originally suggested to me by Pierre Keller.

${ }^{23}$ See also Hegel's characterization of Kantian pure apperception as "the activity of making one's own [die Tätigkeit des Vermeinigens]" (EL\$42Z1).

${ }^{24}$ Fichte (1965: Vol. 4, 257 and 347).

${ }^{25}$ Cf. Quante (2004: 36-8) for a somewhat different understanding of the relation between the theoretical and practical aspects of the will. Briefly, I take the use of the certainty/truth 


\section{Christopher L. Yeomans}

distinction in the first sense of subjectivity to indicate that the form of consciousness is deeply involved in that sense of subjectivity (which Quante re-orders as "Subjective3", rather than being limited to the third sense of subjectivity (Quante's "Subjective2"). A consideration of the relation between PR\$§8 \& 9 further supports my interpretation, since there the owning of the content (the first sense of subjectivity) is said to be the end in accordance with the form of consciousness.

${ }^{26}$ This is an aspect of Hegel's thought that appears to develop quite late in the lectures that lead up to the published text of the Philosophy of Right, since all three of the three objective sides do not yet appear even in the Berlin lectures of 1818/1819.

${ }^{27}$ Despite the apparently contrary remark at the beginning of $\$ 25$, Hegel is at pains (particularly in the Zusatz of \$26) to say that the difference between subjectivity and objectivity is not the distinction between the particular and the universal or general.

${ }^{28}$ Hegel's lecture remarks at VPR III, 161 are particularly helpful here.

29 This is a point grounded in Hegel's theory of absolute modality. See Yeomans (2011, Ch. 7).

${ }^{30}$ For interesting treatments of this issue see Schmidt am Busch (2010 and 2002).

\section{Bibliography}

Bittner, R. (1989), What Reason Demands. Cambridge: Cambridge University Press. Blasche, S. (2004), 'Natural Ethical Life and Civil Society: Hegel's Construction of the Family', in R. Pippin and O. Höffe (eds.), Hegel on Ethics and Politics. Cambridge: Cambridge University Press.

Bloch, E. (1951), Subjekt-Objekt: Erläuterungen zu Hegel. Berlin: Aufbau-Verlag. Chisholm, R. (1976), Person and Object: a Metaphysical Study. London: Allen and Unwin.

Ciavatta, D. (2009), Spirit, the Family, and the Unconscious in Hegel's Philosophy. Albany, N.Y.: State University of New York Press.

Deligiorgi, K. (2010), 'Doing without Agency: Hegel's Social Theory of Action', in A. Laitinen and C. Sandis (eds.), Hegel on Action. New York: Palgrave Macmillan. Fichte, J. H. (1965), Sämmtliche Werke, ed. I. H. Fichte. Berlin: de Gruyter \& Co. Fichte, J. H. (2000), Foundations of Natural Right, ed. F. Neuhouser. Cambridge: Cambridge University Press.

Fichte, J. H. (2005), The System of Ethics, ed. D. Breazeale and G. Zöller. Cambridge: Cambridge University Press.

Hegel, G. W. F. (1971), Werke in zwañig Bänden. ed. E. Moldenhauer and K. M. Michel. Frankfurt a.M.: Suhrkamp.

Hegel, G. W. F. (1974), Vorlesungen über Rechtsphilosophie, ed. K. H. Ilting. Stuttgart: Fromman.

Hegel, G. W. F. (1976), Jenaer Systementwrinfe (Gesammelte Werke, Bd. 8), ed. J. H. Trede and R.-P. Horstmann. Düsseldorf: Rheinisch-Westfälische Akaemie der Wissenschaften. 
Hegel, G. W. F. (2008), Phenomenology of Spirit, tr. Terry Pinkard. Cambridge: Cambridge University Press (forthcoming).

Kant, I. (1996), Practical Philosophy, trans. M. Gregor. Cambridge: Cambridge University Press.

Lukacs, G. (1975), The Young Hegel: Studies in the Relations between Dialectics and Economics, trans. Rodney Livingstone. London: Merlin Press.

Moyar, D. (2011), Hegel's Conscience. Oxford: Oxford University Press.

Pinkard, T. (1996) Hegel's Phenomenology: The Sociality of Reason. Cambridge: Cambridge University Press.

Quante, M. (2004), Hegel's Concept of Action, trans. D. Moyar. Cambridge: Cambridge University Press.

Pippin, R. (1993), 'You Can't Get There from Here: Transition Problems in Hegel's Phenomenology of Spirit, in The Cambridge Companion to Hegel, ed. Frederick C. Beiser. Cambridge: Cambridge University Press, 1993.

Pippin, R. (2009), Hegel's Practical Philosophy. Cambridge: Cambridge University Press.

Rose, D. (2007), Hegel's Philosophy of Right. London: Continuum.

Schmidt am Busch, H.-C. (2002), Hegels Begriff der Arbeit. Berlin: Akademie.

Schmidt am Busch, H.-C. (2010), 'What Does it Mean to "Make Oneself Into An Object"?', in A. Laitinen and C. Sandis (eds.), Hegel on Action. New York: Palgrave Macmillan.

Tolstoy, L. (1995), Anna Karenina, tr. L. \& A. Maude. Oxford: Oxford University Press.

Velleman, D. (2000), 'What Happens when Someone Acts?', in The Possibility of Practical Reason. Oxford: Clarendon Press.

Velleman, D. (2006), Self to Self. Cambridge: Cambridge University Press.

Wood, A. (1990), Hegel's Ethical Thought. Cambridge: Cambridge University Press.

Wright, L. (2011), 'Explanation, Contrast, and the Primacy of Practice', European Journal of Philosophy. doi: 10.1111/j.1468-0378.2011.00472.x

Yeomans, C. (2010), 'Hegel and Analytic Philosophy of Action', The Owl of Minerva 42(1-2), 41-62.

Yeomans, C. (2011), Freedom and Reflection: Hegel and the Logic of Agency. Oxford: Oxford University Press.

Zangwill, N. (2008), 'Besires and the Motivation Debate', Theoria 74: 50-59. 